\title{
Nuclear Dynamics Consequence Analysis (NDCA) for the Disposal of Spent Nuclear Fuel in an Underground Geologic Repository
}

\section{Volume1: Executive Summary}

\author{
Idaho National Engineering and Environmental Laboratory \\ Lockheed Martin Idaho Technologies Company \\ Idaho Falls, Idaho 83415
}

October 1998

This report was not produced under a quality assurance

program that satisfies the requirements of the

National Spent Nuclear Fuel Program and DOE/RW-0333P,

Office of Civilian Radioactive Waste Management Quality

Assurance Requirements Description. Therefore, the data in the report are not considered qualified and are not to be relied upon to

address safety and waste isolation issues until an accepted qualification process has been completed.

Prepared for the

U.S. Department of Energy

Assistant Secretary for Environmental Management

Under DOE Idaho Operations Office

Contract No. DE-AC07-94ID13223 


\section{DISCLAIMER}

Portions of this document may be illegible in electronic image products. Images are produced from the best available original document. 


\section{SANDIA REPORT}

SAND98-2208/1 • UC-900

INEEL/EXT-98-00996

Unlimited Release

Printed October 1998

\section{Nuclear Dynamics Consequence Analysis (NDCA) for the Disposal of Spent Nuclear Fuel in an Underground Geologic Repository}

\section{Volume 1: Executive Summary}

Lawrence C. Sanchez

Jonathan S. Rath

Richard Aguilar

Holly R. Trellue

Kyle Cochrane

Larry L. Taylor

Jim R. Wilson

\section{Prepared by}

Sandia National Laboratories

Abuquerque, New Mexico 87185 and Livemore, California 94550

Sandia is a multiprogram laboratory operated by Sandia Corporation,

a Lockheed Martin Company, for the United States Department of

Energy under Contract DE-AC04-94AL85000.

Approval for public release; further dissemination unlimited.

\section{Sandia National Laboratories}


Issued by Sandia National Laboratories, operated for the United States Department of Energy by Sandia Corporation.

NOTICE: This report was prepared as an account of work sponsored by an agency of the United States Government. Neither the United States Government nor any agency thereof, nor any of their employees, nor any of their contractors, subcontractors, or their employees, makes any warranty, expressed or implied or assumes any legal liability or responsibility for the accuracy, completeness, or usefulness of any information, apparatus, product, or process disclosed, or represents that its use would not infringe privately owned rights. Reference herein to any specific commercial product, process, or service by trade name, trade mark, manufacturer, or otherwise, does not necessarily constitute or imply its endorsement, recommendation, or favoring by the United States Government, any agency thereof, or any of their contractors or subcontractors. The views and opinions expressed herein do not necessarily state of reflect those of the United States Government, any agency thereof, or any of their contractors.

Printed in The United States of America. This report has been reproduced directly from the best available copy.

Available to DOE and DOE contractors from

Office of Scientific and Technical Information

P. O. Box 62

Oak Ridge, TN 37831

Prices available from (615) 576-8401, FTS 626-8401 


\title{
Nuclear Dynamics Consequence Analysis (NDCA) for the Disposal of Spent Nuclear Fuel in an Underground Geologic Repository
}

\section{Volume 1: Executive Summary}

\author{
Lawrence C. Sanchez ${ }^{(1)}$ \\ Jonathan S. Rath ${ }^{(2)}$ \\ Richard Aguilar ${ }^{(2)}$ \\ Holly R. Trellue ${ }^{(1)}$ \\ Kyle Cochrane $e^{(1)}$ \\ Larry L. Taylor ${ }^{(3)}$ \\ Jim R. Wilson ${ }^{(3)}$ \\ ${ }^{(1)}$ WIPP Performance Assessment Departments 6848/6849 \\ Repository Nuclear Analysis Group \\ Sandia National Laboratories \\ ${ }^{(2)}$ New Mexico Engineering Research Institute \\ Albuquerque, NM 87185 \\ (3)Idaho National Engineering and Environmental Laboratory \\ Idaho Falls, ID 83415
}

\begin{abstract}
The United States Department of Energy Office of Environmental Management's (DOE/EM's) National Spent Nuclear Fuel Program (NSNFP), through a collaboration between Sandia National Laboratories (SNL) and Idaho National Engineering and Environmental Laboratory (INEEL), is conducting a systematic Nuclear Dynamics Consequence Analysis (NDCA) of the disposal of SNFs in an underground geologic repository sited in unsaturated tuff. This analysis is intended to provide interim guidance to the DOE for the management of the SNF while they prepare for final compliance evaluation. This report presents results from a Nuclear Dynamics Consequence Analysis (NDCA) that examined the potential consequences and risks of criticality during the longterm disposal of spent nuclear fuel owned by the U.S. Department of Energy's Office of
\end{abstract}


Environmental Management (DOE/EM). This analysis investigated the potential of postclosure criticality, the consequences of a criticality excursion, and the probability frequency for post-closure criticality. The results of the NDCA are intended to provide the DOE/EM with a technical basis for measuring risk which can be used for screening arguments to eliminate post-closure criticality FEPs (features, events and processes) from consideration in the compliance assessment because of either low probability or low consequences.

\section{Preface}

The purpose of this 1997 criticality study is to identify for the U. S. Department of Energy (DOE) the potential for criticality and the consequences of defense spent nuclear fuel (DNSF) and defense high-level waste (DHLW) after disposal. The disposal site under study is the potential repository in unsaturated tuff at Yucca Mountain, Nevada. The study is part of a broader DOE program, the National Spent Nuclear Fuel Program (NSNFP), for developing a safe, cost-effective technical strategy for the interim management and ultimate disposition of the foreign and domestic spent nuclear fuel (SNF) under the DOE's jurisdiction. The DOE-owned DNSF and DHLW are currently stored at the Idaho National Engineering and Environmental Laboratory (INEEL), the Hanford Waste Vitrification Plant (HWVP), the Savannah River Plant, and other DOE sites. The SNF originated in military and experimental reactors; the high-level waste (HLW) was generated during reprocessing of the SNF.

\section{Organization of Report}

The executive summary (Volume 1) reviews the scope and method of analyses, but its emphasis is on the important ideas and conclusions of the Nuclear Dynamics Consequences Analysis (NDCA). Volume 2 is a detailed account of the NDCA. Chapter 1 provides an overview of the study, its technical objectives, and a description of the models. Chapter 2 outlines the current status of related regulations and the relationship of this study to other analyses. Chapters 3 through 6 describe the models used in the NDCA, the static criticality model (CX), the nuclear dynamics models (UDX/DTHX), the thermal-hydrologic transport model (THX), and the probability model (PRA). Results are stmmarized in Chapter 7. Conclusions and recommendations are presented in Chapter 8. The appendices provide supporting technical data.

\section{Suggested Use of Report}

- For a summary of the results, refer to the Executive Summary (Volume 1).

- For an overview of the entire criticality analysis process, refer to Chapter 1, Introduction (Volume 2). 
- For specific details pertaining to analysis models, refer to the individual chapters and appendices (Volume 2).

\section{Related Documents}

The criticality study is an integral part of the performance assessment (PA) of DOEowned DSNF/DHLW in the potential Yucca Mountain repository. The current PA (Rechard 1997) is the third phase of a study that was begun in 1993. The 1993 PA evaluated waste treatment options, ranging from no condition to codisposal to full reprocessing, by studying the performance of five potential waste forms. For the 1993 PA, 12,000 metric tons of heavy metal (MTHM) of waste were emplaced in two hypothetical repositories, one sited in granite (saturated) and the other in salt. In the 1994 PA, Sandia National Laboratories (SNL) assessed one treatment option (direct disposal) for five types of SNF and three treatment options for calcined HLW in a 12,000-MTHM hypothetical repository in unsaturated tuff. The PAs were documented in the following reports:

Rechard, R. P., ed. 1993. Initial Performance Assessment of the Disposal of Spent Nuclear Fuel and High-Level Waste Stored at Idaho national Engineering Laboratory, Vols. 1 and 2. SAND93-2330. Albuquerque, NM: Sandia National Laboratories.

Rechard, R. P., ed. 1995. Performance Assessment of the Direct Disposal in Unsaturated Tuff of Spent Nuclear Fuel and High-Level Waste Owned by the

U. S. Department of Energy, Vols. 1, 2, and 3. SAND94-2563. Albuquerque, NM: Sandia National Laboratories.

The major source of data for site characterization of the tuff repository was drawn from SNL's PAs' of the Yucca Mountain Project:

Wilson et al. 1994. Total System Performance Assessment for Yucca MountainSNL Second Iteration (TSPA-1993). SAND93-2675. Albuquerque, NM: Sandia National Laboratories.

Some parameters for the 1997 PA are based on the results from an abbreviated PA performed for the Yucca Mountain Project in 1996 (a-TSPIA-1996):

- The SNL Performance Assessment Departments for the Yucca Mountain Project (YMP) and the Waste Isolation Pilot Plant (WIPP) Project are both within the Nuclear Waste Management Center. Their style of calculations differ because of the stage of the projects, degree of scientific understanding of unsaturated low, and specific requests from their respective DOE sponsors. 
M\&O (Civilian Radioactive Waste Management System, Management and Operating Contractor [CRWMS M\&O]). 1996, in preparation (August 15, 1996, preliminary draft). "Description of Performance Allocation." B00000000-017172200-00177. Rev. 00. Las Vegas, NV: U. S. Department of Energy, Yucca Mountain Site Characterization Project.

All three of Sandia's DNSF/DHLW studies (1993, 1994, and 1997 PAs) used the PA methodology originally developed for the study of the Waste Isolation Pilot Plant (WIPP), near Carlsbad, NM; thus, a useful companion document that reviews the mechanics of the PA process is

Rechard, R. P. 1995. An Introduction to the Mechanics of Performance Assessment Using Examples of Calculations Done for the Waste Isolation Pilot Plant Between 1990 and 1992. SAND93-1378. Albuquerque, NM: Sandia National Laboratories. 


\section{CONTENTS}

Page

Volume 1

Executive Summary $\quad$ ES-1

ES.1 Purpose ES-1

ES.2 Introduction ES-1

ES.3 Criticality Geometries $\quad$ ES-3

ES.3.1 Internal ES-3

ES.3.2 Near-Field $\quad$ ES-3

ES.3.3 Far-Field ES-3

ES.4 Models Used and Analysis Codes Used for Criticality Analysis ES-5

ES.4.1 CX Model (Criticality Potential Model) ES-5

ES.4.2 THX Model (Thermal Hydrology Model) ES-9

ES.4.3 UDX Model (Uncoupled Nuclear Dynamics Model) ES-9

ES.4.4 DTHX Model (Fully-Coupled Nuclear Dynamics Model) ES-9

ES.4.5 PRA Model (Probabilistic Risk Analysis Model) ES-9

ES.5 Results ES-10

ES.5.1 Criticality Potential Parametric Study ES-10

ES.5.2 Excursion Consequences ES-11

ES.5.3 Thermal Hydrology Simulations ES-13

ES.5.4 Probability for Criticality Initiators $\quad$ ES-14

ES.5.5 General Results ES-14

ES.6 Conclusions ES-15

ES.7 Potential Benefits of Model Enhancements ES-15

ES.8 References $\quad$ ES-16

\section{Volume 2}

1 Introduction 1 - 1

2 Background Information 2 - 1

3 Criticality Potential (CX) Model 3 - 1 
4 Nuclear Dynamics (UDX/DTHX) Models 4 - 1

5 Thermal Hydrology (THX) Model 5 - 1

6 Probabilistic (PRA) Model 6 - 1

7 Summary of Results 7 -1

8 Conclusions and Recommendations 8 - 1

9 References $9-1$

Volume 3

APPENDICES

Appendix A - - Acronyms and Abbreviations

Appendix B -- Background on PA Process

Appendix C -- Fission Source Term

Appendix D -- Identification of Risks Due to Releases to Biosphere

Appendix E -- CX Model (RKeff/MCNP)

Appendix F -- $\quad$ UDX Model (NARK)

Appendix G -- THX Model (BRAGFLO_T)

Appendix H - $\quad$ PRA Model (SLAM) 


\section{Figures}

Page

ES-1 Integration of nuclear criticality analysis into repository performance assessment.

ES-2

ES-2 Typical criticality curve for a fixed fissile concentration. ES-6

ES-3 Typical criticality surface for a selections of fissile concentrations. ES-7

ES-4 Typical near-field criticality S-curve. $\quad$ ES-7

ES-5 Typical far-field criticality S-curve (extracted from the criticality $\begin{array}{ll}\text { surface of Figure ES-3). } & \text { ES-8 }\end{array}$

ES-6 Typical criticality saddle generated from a series of criticality S-curves for various fissile enrichments.

ES-8

ES-7 Comparison of fully-coupled nuclear dynamics results with uncoupled nuclear dynamics results.

ES-12

ES-8 Scaling law for uncoupled nuclear dynamics calculations.

ES-13

ES-9 Typical thermal hydrology/groundwater transport computational results. ES-14

\section{Tables}

Page

ES-1 YMP-Scale Inventory of SNF and HIL Materials

ES-4 


\section{NUCLEAR DYNAMICS CONSEQUENCE ANALYSIS (NDCA) FOR THE DISPOSAL OF SPENT NUCLEAR FUEL IN AN UNDERGROUND GEOLOGIC REPOSITORY}

\section{EXECUTIVE SUMMARY}

\section{ES.1 Purpose}

This report presents results from a Nuclear Dynamics Consequence Analysis (NDCA) that examined the potential consequences, and risks, of criticality, during the long-term disposal of spent nuclear fuel owned by the U.S. Department of Energy's Office of Environmental Management (DOE/EM). This analysis investigated the potential of postclosure criticality, the consequences of a criticality excursion, and the probability frequency for post-closure criticality. The results of the NDCA are intended to provide the DOE/EM with a technical basis for measuring risk which can be used for screening arguments to eliminate post-closure criticality FEPs (features, events and processes) from consideration in the compliance assessment because of either low probability or low consequences.

\section{ES.2 Introduction}

This report discusses the post-closure nuclear criticality aspects of DOE-owned spent nuclear fuel (DSNF) in a disposal system similar to the potential repository at Yucca Mountain Site (YMS). The results of this study are intended to be combined with a performance assessment (PA) of long term disposal of the DSNF in the potential repository. The performance assessment is used to help guide DOE/EM with its concerns regarding the preparation of DSNF for permanent disposal. The DSNF and defense high level waste (DHLW) studied in this report are currently stored at the Idaho National Engineering and Environmental Laboratory (TNEEL), the Hanford reservation, the Savannah River Site, other DOE sites, and universities.

The overall findings of this report is that nuclear criticality is not a significant contributor to post-closure repository releases to the accessible environment. The risks of criticality, measured in the metric of additional fissions, are below the roundoff of the inventory source term. The results reported here correspond to extensive parametric studies that span expected ranges for physical conditions, such as fissile mass, fissile concentration, enrichment, porosity of assembly, groundwater, and saturation. The data are present to allow insight into key aspects to be considered with regard to criticality in a geologic repository.

In this report, the term "criticality" applies to geologic repository performance assessment. For geologic repositories, criticality means consequences of an actual criticality (rather than criticality safety as defined for surface storage). When the consequences of criticality are combined with probability frequency, as calculated through a probabilistic risk assessment (PRA), the result is a risk measure. The metric 
used is additional fissions, which can be directly compared to the initial radiological source term. Currently, probability frequencies for these consequences indicate that any additional fissions are unlikely to add to the surface biological hazards caused by the disposal of SNF and HLW materials. The results of this study were formulated for use in the support of the features, events, and processes (FEPs) screening arguments to eliminate criticality as an event for consideration in the performance assessment of the potential repository at the Yucca Mountain Site. Figure ES-1 identifies the integration of criticality data into the DSNF PA. The FEPs screening arguments for nuclear criticality can be based on low: 1) probability of occurrence (criticality potential), and/or 2) consequences of occurrence (nuclear dynamics).

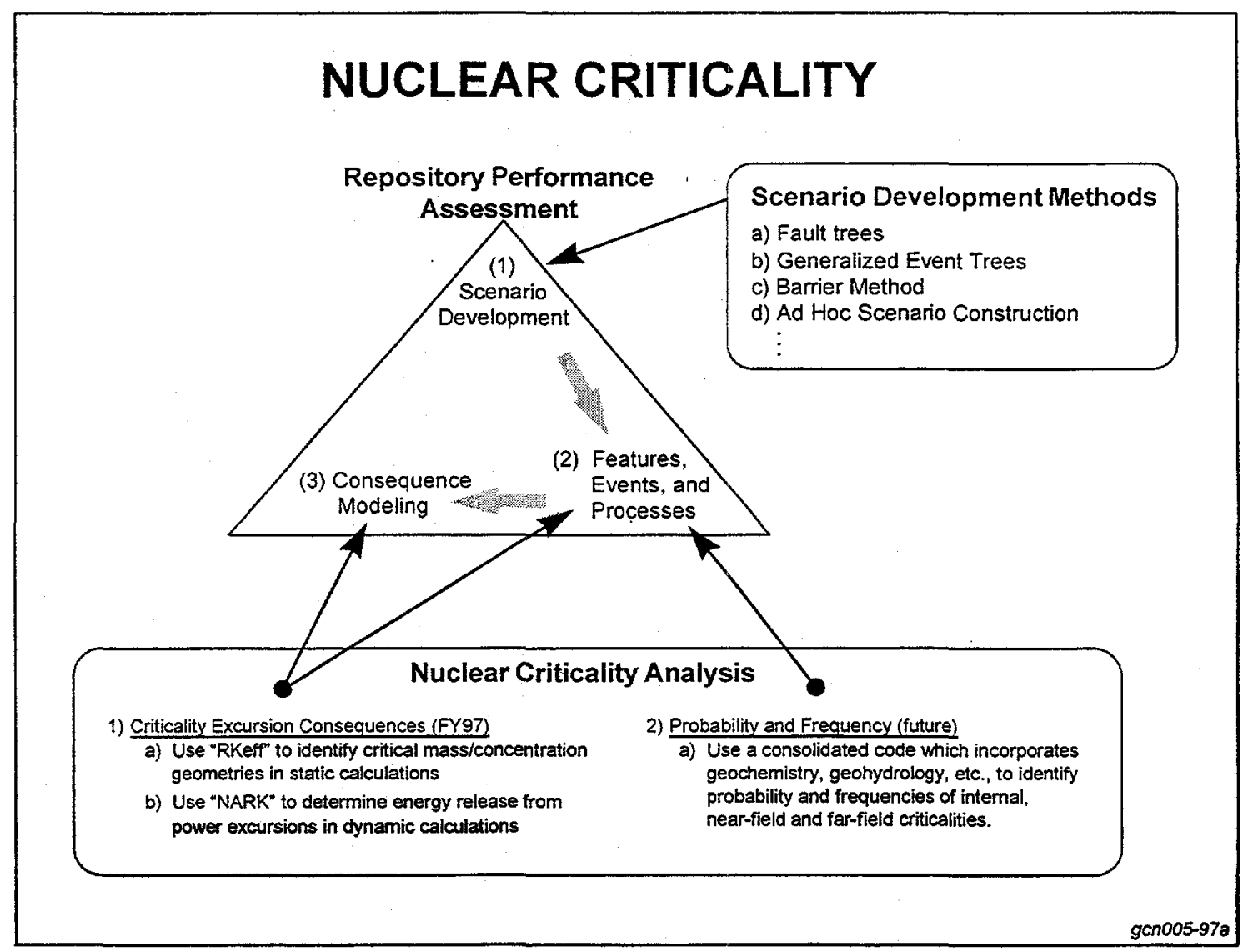

Figure ES-1. Integration of nuclear criticality analysis into repository performance assessment. 


\section{ES.3 Criticality Geometries}

In the NDCA, the measure of risk was calculated for criticality during long-term disposal of DSNF. First, the potential for criticality was calculated. In the modeled repository, the waste containers are assumed to be placed on concrete piers. For analysis, nuclear criticality was assumed to occur at three locations:

\section{ES.3.1 Internal}

Internal geometries are where the fissile material is still in the original container. The SNF container and its internal components (fuel elements, grid spacers, etc.) may be corroded or degraded, but the waste container structure would remain in its original location and produce the highest fissile atom-density for any geometry. Key aspects of this scenario include:

a) Method of waste container corrosion (e.g., canister corrosion from the bottom upward versus from the top downward).

b) Transport of neutron poison compared to fissile material transport.

\section{ES.3.2 Near Field}

Near-field geometries are where the fissile material is no longer in the waste container structure in the original location but is within one tunnel diameter of the original location. The near-field geometries investigated in this study were:

a) Rust/uranium near-field in which the container is completely corroded and yields a hemispherical slump of rust and fissile material. This geometry was analyzed for various conditions, e.g., reflection, saturation, and addition of neutron poisons.

b) Concrete/uranium near-field in which the fissile material has migrated from the original container and/or rust slump into the concrete inverts within the repository.

\section{ES.3.3 Far-Field}

Far-field geometries are where the fissile material has been transported via groundwater to distant locations where it may have reconcentrated in pores, fractures, or rock vugs due to precipitation, mineralization, or any other process. A key aspect of this type of criticality is the enrichment of the fissile material at these distant locations. For significant fissile mass to concentrate at these locations, the corrosion leachate plumes from multiple containers must commingle through a common drain. Since the DOEowned SNFs are to be dispersed among commercial SNFs, the commingled leachate will have a low enrichment. Even more importantly, highly-enriched SNFs will be placed in containers with DHLW as a dilutant. Hence, various fissile enrichments were investigated in order to identify far-field enrichment limits which can be compared to repository average enrichments (see Table ES-1). It is important to note that even though the average void space for the Topopah Springs tuff is $13.9 \%$, there is no indication that water driven fissile movement can uniformly distribute within the tuff. Also, not all of the pore spaces are interconnected for both transport and/or accumulation of either fissile material or water. 


\section{Table ES-1. YMP-Scale Inventory of SNF and HLW Materials (Calendar Year $=2035$, Time $=0 \mathrm{yr}$ )}

(a)

\begin{tabular}{|c|c|c|c|c|c|c|c|}
\hline Category & \multicolumn{6}{|c|}{ YMP-Scale Spent Nuclear Fuels and High-Level Wastes } & (b) \\
\cline { 2 - 7 } & Material Type & $\begin{array}{c}\text { No. } \\
\text { Waste } \\
\text { Packages }\end{array}$ & $\begin{array}{c}\text { Metric Tons } \\
\text { Th, Pu \& U }\end{array}$ & $\begin{array}{c}\text { Total } \\
\text { Inventory } \\
\text { [Curies] }\end{array}$ & $\begin{array}{c}\text { Source } \\
\text { EPA } \\
\text { Units (e) }\end{array}$ & $\begin{array}{c}\text { Fissile } \\
\text { Mass } \\
\text { Equil. }\end{array}$ & $\begin{array}{c}\text { Enrich- } \\
\text { ment }\end{array}$ \\
\hline
\end{tabular}

DOE-Owned Spent Nuclear Fuels \& High-Level Wastes

\begin{tabular}{|c|c|c|c|c|c|c|c|}
\hline $\begin{array}{c}1 \\
2 \\
3 \\
4 \\
5 \\
6 \\
7 \\
8 \\
9 \\
10 \\
11 \\
12 \\
13 \\
16\end{array}$ & $\begin{array}{l}\text { Uranium-metal/Zirconium } \\
\text { Uranium-Zirconium/Zirconium } \\
\text { Uranium-Molybdenum/Zirconium } \\
\text { Uranium-Oxide/Zirconium/ss } \\
\text { Uranium-Oxide/Al } \\
\text { Uranium-Alx/Al } \\
\text { Uranium-Silicon } \\
\text { Uranium/Thorium C(hi)/G } \\
\text { Uranium/Thorium C(li)/G } \\
\text { Uranium\&Uranium;Pu C/non-G } \\
\text { MOx/Zirconium-ss } \\
\text { Uranium/Thorium oxide/Zr-ss } \\
\text { Uranium-Zirconium-Hx/ss,inc } \\
\text { High-Level Waste (c) }\end{array}$ & $\begin{array}{c}118 \\
9 \\
55 \\
203 \\
595 \\
750 \\
255 \\
545 \\
103 \\
5 \\
352 \\
69 \\
102 \\
-\end{array}$ & $\begin{array}{l}2.13 \mathrm{E}+03 \\
3.84 \mathrm{E}-02 \\
4.21 \mathrm{E}+02 \\
7.94 \mathrm{E}+01 \\
8.81 \mathrm{E}+01 \\
9.08 \mathrm{E}+00 \\
1.26 \mathrm{E}+01 \\
2.44 \mathrm{E}+01 \\
1.61 \mathrm{E}+00 \\
5.66 \mathrm{E}-02 \\
3.93 \mathrm{E}+00 \\
5.55 \mathrm{E}+01 \\
2.20 \mathrm{E}+00 \\
9.41 \mathrm{E}+03\end{array}$ & & & & \\
\hline & Sub-Total & 3,161 & $\begin{array}{c}1.22 E+04 \\
(16.3 \%) \\
\text { (d) }\end{array}$ & $\begin{array}{c}1.81 \mathrm{E}+08 \\
(1.4 \%)\end{array}$ & $\begin{array}{c}3.29 \mathrm{E}+03 \\
(1.1 \%)\end{array}$ & $\begin{array}{l}1.54 \mathrm{E}+05 \\
(10.5 \%)\end{array}$ & $\begin{array}{l}(5.5 \%) \\
\text { mixture }\end{array}$ \\
\hline \multicolumn{8}{|c|}{ Commercial Spent Nuclear Fuels } \\
\hline \multirow[t]{2}{*}{$\begin{array}{l}14 \\
15\end{array}$} & $\begin{array}{l}\text { Commercial-PWR } \\
\text { Commercial-BWR }\end{array}$ & $\begin{array}{l}4820 \\
2859\end{array}$ & $\begin{array}{l}4.14 E+04 \\
2.16 E+04\end{array}$ & & & & \\
\hline & Sub-Total & 7,679 & $\begin{array}{c}6.30 \mathrm{E}+04 \\
(83.7 \%)\end{array}$ & $\begin{array}{c}1.23 \mathrm{E}+10 \\
(98.6 \%)\end{array}$ & $\begin{array}{c}2.84 \mathrm{E}+05 \\
(98.9 \%) \\
\end{array}$ & $\begin{array}{c}1.32 \mathrm{E}+06 \\
(89.5 \%) \\
\end{array}$ & $\begin{array}{l}(2.1 \%) \\
\text { mixture }\end{array}$ \\
\hline \multicolumn{2}{|c|}{ Potential YMP Site Total } & 10,840 & $7.52 E \div 04$ & $\begin{array}{c}1.25 E+10 \\
(=6.43 E+31 \\
\text { fissions })\end{array}$ & $2.88 E+05$ & $1.47 \mathrm{E}+06$ & $\begin{array}{l}(2.2 \%) \\
\text { mixture }\end{array}$ \\
\hline
\end{tabular}

ss Stainless steel, $\mathbf{A l}$ - aluminum, $\mathrm{Hx}$ - hydride, $\mathbf{A l x}$ - aluminum oxide

(a) Data in this table was taken from the 1997 DSNF/DHLW PA Database prior to finalization of data information. Values may vary slightly from final published version: Rechard et. al., 1997.

(b) For details on computed values, see Appendix C.

(c) Category 16 represents the HLW, which is co-disposed with Categories 2 through 13 of DSNF. (See Table 3-4 of Ref. Rechard et. al., 1998 for more information). There are up to 13,920 containers of HLW for the codisposed option with DSNF in categories 1 through 13.

(d) Note, only $4.4 \%$ of the MT (Th, Pu \& U) are due to DOE-owned inventory. Up to $10 \%$ (7,000 MT of Th, Pu \& $\mathrm{U})$ of design limit is allocated for DOE owned inventory. 
(e) Even though EPA units (doses surrogate for health risks) are no longer applicable to YMP (i.e., 40 CFR 191 was remanded for application to YMP), they are presented here to illustrate that DOE-owned inventory represents approximately one part in a hundred of the overall risks. 


\section{ES.4 Models Used and Analysis Codes Used for Criticality Analysis}

Five models were used in the NDCA computational effort to model SNF that exhibit negative thermal feedback effects. These models were needed to perform the large number of calculations for nuclear criticality potential, consequences of an individual nuclear excursion, probabilities for initiation of a criticality, and probability frequencies for continuous criticalities. A brief description of these models is listed below:

\section{ES.4.1 CX Model (Criticality Potential Model)}

The CX model uses two major computational codes: RKeff (generated as part of the NDCA project) and MCNP (an existing industry standard code for neutral particle transport). The RKeff code was developed as a pre- and post-processor for eigenvalue (static criticality, $\mathrm{k}_{\mathrm{eff}}$ ) calculations which identify the criticality potential of a fissile assembly. The code requires up to twelve input variables including: fissile mass, fissile concentration, model geometry shape, and saturation in the rock matrix. RKeff generates complete MCNP input files that are then used to identify whether an assembly of fissile material is subcritical, critical, or supercritical. Results are processed to identify critical fissile mass and concentration values necessary for given geologic conditions to result in a critical assembly. The critical mass and concentration values are then used in the THX, UDX, and DTHX models. The CX calculations were performed in a four step process:

A) A 3-D MCNP model is generated for a baseline case study, which has a set of fixed parameters such as fissile material, enrichment, host rock type, and geologic quantities such as porosity and saturation. Then, for a fixed fissile concentration, a series of static criticality calculations were performed for various masses. These values are plotted in a two dimensional curve termed a "criticality curve". A typical criticality curve can be seen in Figure ES-2.

B) A new fissile concentration value is identified and the processes in Step A are repeated. This is performed for a multitude of concentration values and the results represent a two-dimensional parametric study of $k_{\text {eff }}$ as a function of fissile mass and fissile concentration. The results can be plotted as three dimensional curves termed "criticality surfaces", which are accumulations of criticality curves. Typical results can be seen in Figure ES-3.

C) Using results from Step B, a criticality buckling search is performed. This corresponds to the identification of sets of fissile mass and concentration values that are necessary to yield a critical assembly (i.e., $k_{\text {eff }}=1.0$ ). The results can be plotted in a two-dimensional curve termed a "criticality S-curve". Typical results from this step can be seen in Figures ES-4 and ES-5.

D) A set of S-curves (from Step C) can be obtained for a variation in a baseline parameter such as fissile enrichment. The results are plotted in a 3-D curve termed a "criticality saddle". Typical results can be seen in Figure ES-6.

From the above description it can be recognized that the development of criticality Scurves and saddles requires a large computational effort since each point on these curves corresponds to an eigenvalue search. In this study, key S-curves were generated for fissile material in near-fields consisting of rust and concrete host rock materials and also 
for far-fields consisting of Topopah Springs tuff host rock (see Chapter 3). These calculations identify which mixtures of fissile material and host rock that could not generate a criticality assembly. The masses for those situations that may yield a critical assembly are the basis for thermal hydrology and nuclear dynamic calculations.

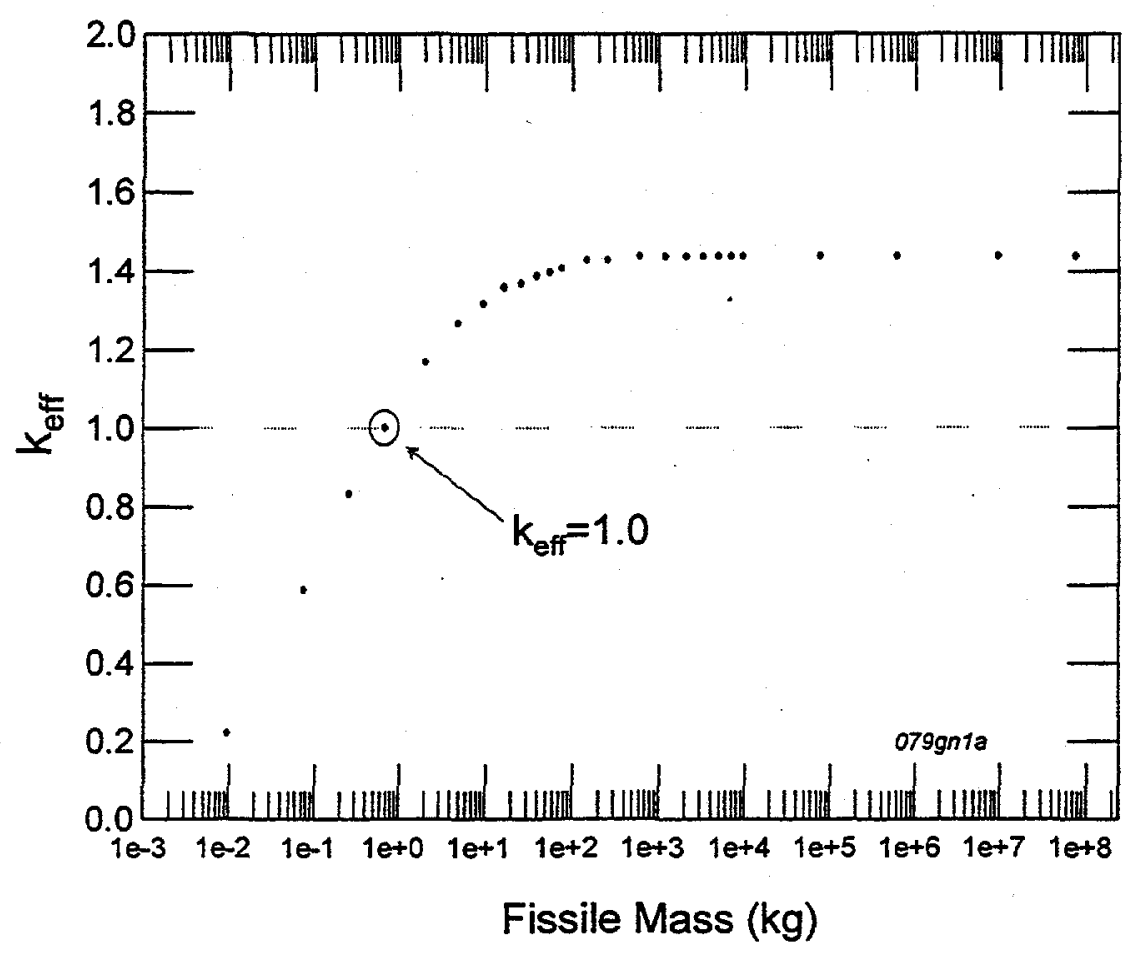

Figure ES-2. Typical criticality curve for a fixed fissile concentration. (Data for 3\% enriched uranium in Topopah Springs tuff at nominal geologic conditions.) 


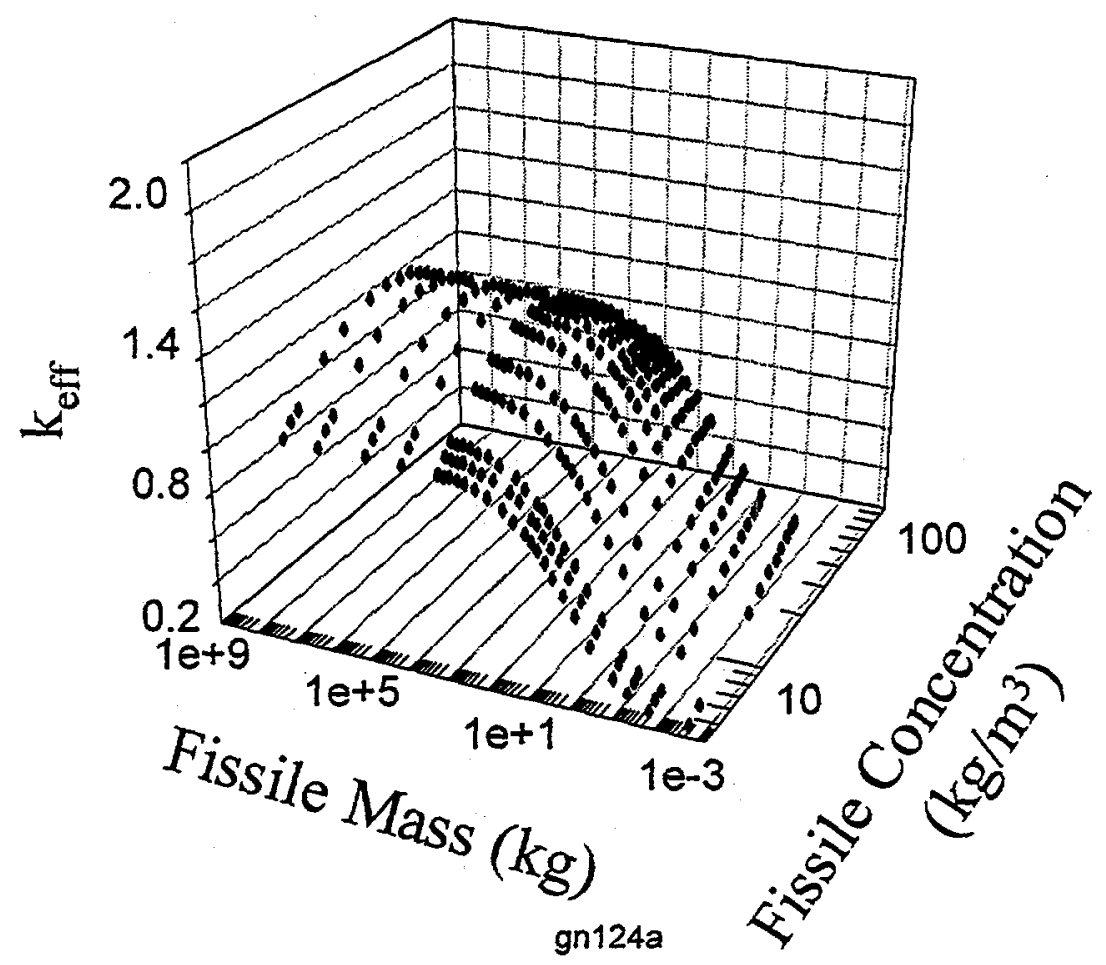

Figure ES-3. Typical criticality surface for a selection of fissile concentrations. (Data for $3 \%$ enriched uranium in Topopah Springs tuff at nominal geologic conditions.)

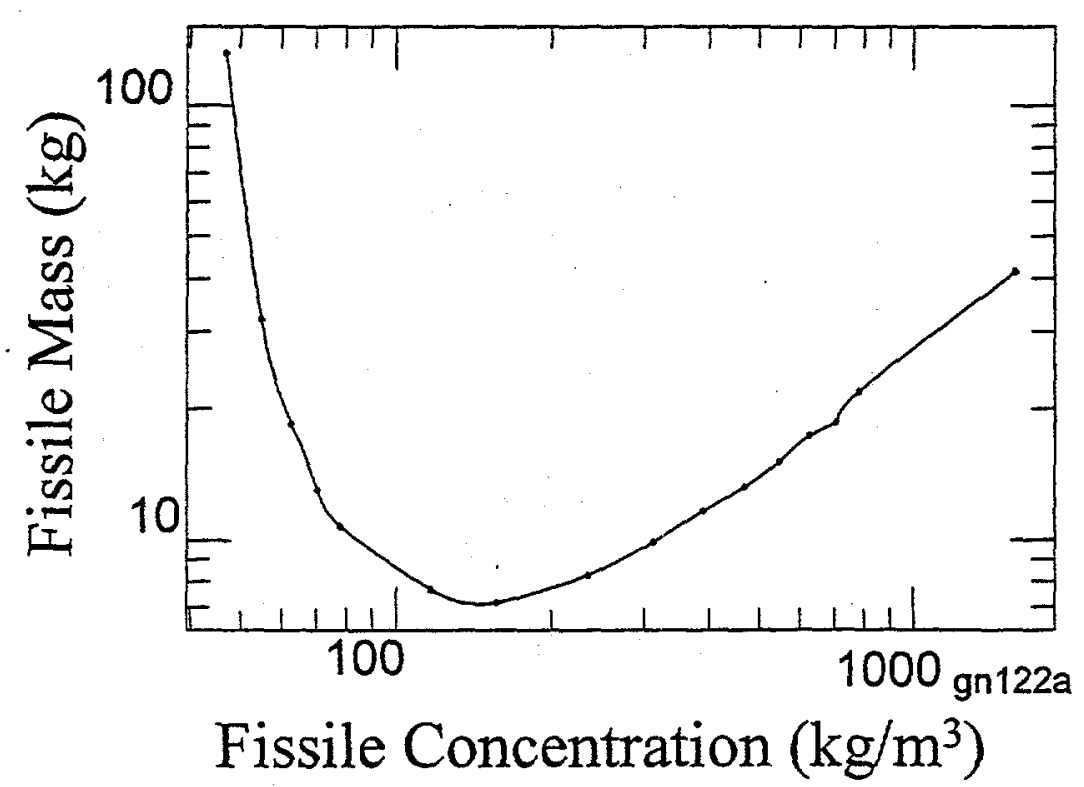

Figure ES-4. Typical near-field criticality S-curve. (Data for highly-enriched uranium in rust at nominal conditions). 


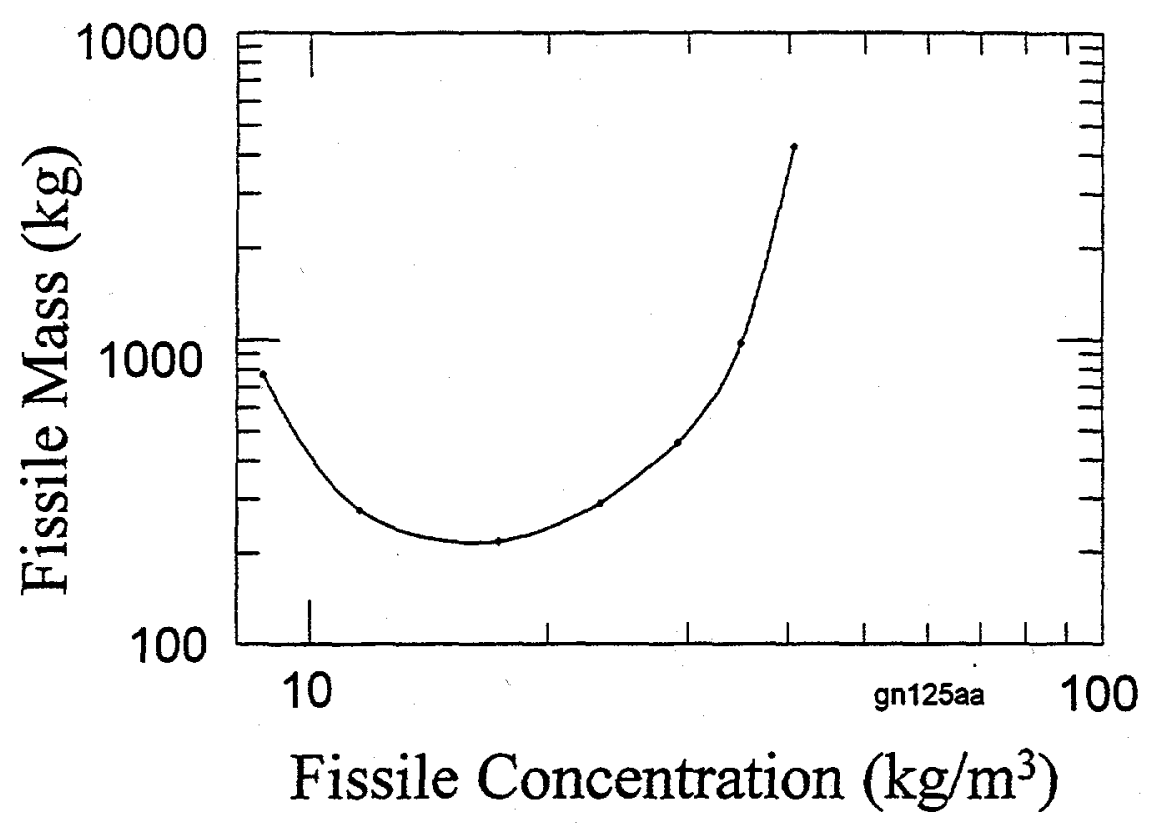

Figure ES-5. Typical far-field criticality S-curve (extracted from the criticality surface of Figure ES-3). (Data for 3\% enriched uranium in Topopah Springs tuff at nominal geologic conditions. Note difference in minima of this S-curve to that from Figure ES-4.)

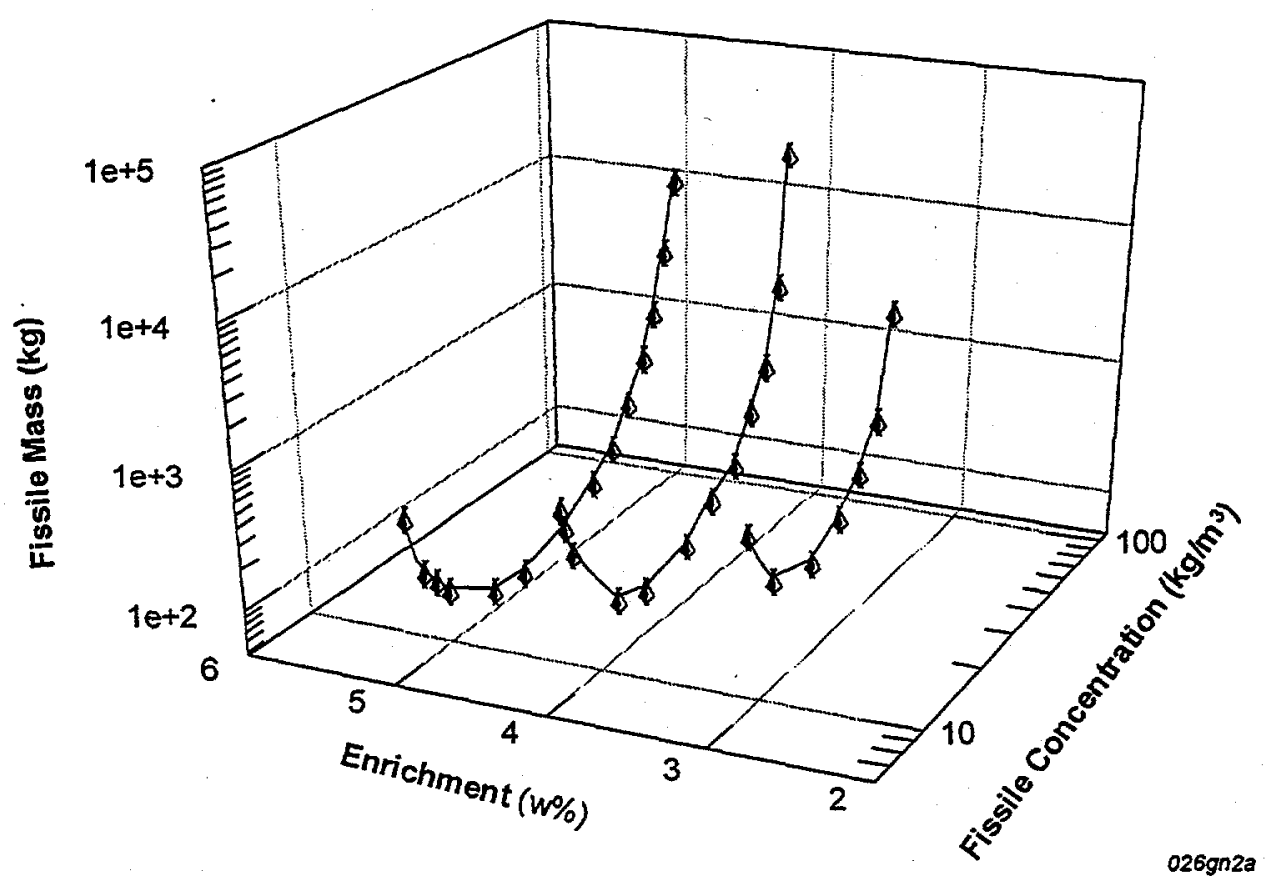

Figure ES-6. Typical criticality saddle generated from a series of criticality S-curves for various fissile enrichments. (Data for uranium in Topopah Springs tuff at nominal conditions.) 


\section{ES.4.2 THX Model (Thermal Hydrology Model)}

The THX model determines the transient thermal and groundwater response of farfield geologic media to a nuclear excursion. This model uses a high spatial resolution version of the computational code BRAGFLO_T, which is an existing Sandia National Laboratories code, to analyze the transient 2-phase flow of groundwater and gas resulting from typical excursions predicted by the UDX model. The results identified the time behavior of temperature for the fissile assembly zone and the groundwater saturation. From these results, the maximum frequency of occurrence of nuclear excursions could be estimated for far-field scenarios, given temperature recovery and resaturation behavior (see Figure ES-9).

\section{ES.4.3 UDX Model (Uncoupled Nuclear Dynamics Model)}

The UDX model uses the computational code NARK, which was generated as part of the NDCA project. This code was developed to determine the transient behavior (nuclear dynamics) of the neutron population in a critical assembly (uncoupled from groundwater effects) by using the classical point-reactor model. Output from NARK is used to identify the power history of a nuclear excursion, total number of fissions from the excursion, and the duration of a single excursion. Input parameters include: fissile material type, delayed neutron lifetimes, half-lives of delayed neutron groups, initial conditions (power, reactivity, and select output from the RKeff code (e.g., fissile mass).

\section{ES.4.4 DTHX Model (Fully-Coupled Nuclear Dynamics Model)}

The DTHX model is comprised of the THX and UDX models coupled together resulting in the code DINO. This computational code was generated from the NARK and BRAGFLO_T codes. It models fully-coupled (neutronics and repository response) far-field nuclear dynamics excursions. Since this computational code is large and is computationally intensive, it was only used for a small set of analysis runs. The output was compared to results from UDX model and identified that UDX results give conservative estimates of the transient behavior of the neutron population during an excursion. Thus, large parametric studies for excursion consequences could be obtained from UDX model.

\section{ES.4.5 PRA Model (Probabilistic Risk Analysis Model)}

The PRA model uses the Monte Carlo simulation code SLAM, which is an existing Idaho National Engineering and Environmental Laboratory code. It was used to model time-dependent events such as groundwater infiltration, canister degradation, SNF cladding degradation, dissolution of fissile material, radionuclides, neutron poison material, etc., and transport of the material to other geologic locations. For the PRA analyses, fault/event tree methodology was combined with the use of the Monte Carlo simulations performed with SLAM (see Chapter 6). Although there is good confidence in the computational code used in the model, there is considerable 
uncertainty in the input data used at this time and the results are considered to be at the ROM (rough-order-of-magnitude) level. Ongoing work in this area should yield updated model results in the future. The most important result produced from this model is the estimated probabilities for initiation of a criticality.

\section{ES.5 Results}

The general findings from this study are as follows: Near-field or internal criticality is possible only if significant separation of fissile material and neutron absorbers occur by chemical processes and/or other mechanisms. The consequences of a critical excursion are minimal in terms of energy release (temperature rise) and impact on fission yield product inventories for plausible conditions. The probabilities for criticality initiators were determined to be very small. The net impact of the resulting criticality fissions on the radiological source term is very small and may not contribute to overall repository performance assessment. Contributions to the annual effective dose by criticality are less than the round-off of the computed PA values. Several specific findings are itemized below:

\section{ES.5.1 Criticality Potential Parametric Study}

Over 30,000 eigenvalue calculations for the fissile material/geometries were investigated using the $\mathrm{CX}$ model. These calculations were used to identify the relationship between fissile mass and fissile concentration necessary to yield a critical assembly. Figures ES-2 to ES-6 are examples of typical results identifying the relationship between fissile mass and concentrations. In the NDCA study, S-curves were generated for over 30 scenarios corresponding to fissile material in near-fields consisting of rust and concrete/"host rock" materials and also for far-fields consisting of Topopah Springs tuff host rock. The following key criticality features were identified from the S-curves:

A) Low enrichment fissile material (less than $2 \%$ enrichment) do not achieve delayed criticality in far-field geometries, even for infinite geometries. Enrichments greater than $2 \%$ will require significant fissile mass quantities, which may not be possible to accumulate in a single concentrated far-field location. PA results should identify that the required accumulation of fissile material is not possible.

B) Generating a critical assembly requires substantial fissile mass and concentration in combination with ideal conditions (i.e., worst-case geometries, significant moderation due to groundwater, removal of neutron poisons, etc.,). For far-field locations, fissile concentrations greater than $7 \mathrm{~kg} / \mathrm{m}^{3}$ are required and depending on the enrichment, fissile masses greater than $200 \mathrm{~kg}$ may also be required for expected far-field enrichments (Figure ES-5). For near-field locations that involve rust slumps, very large fissile concentrations, greater than $50 \mathrm{~kg} / \mathrm{m}^{3}$, are required. The fissile mass necessary for criticality for the near-field is strongly dependent on the enrichment of the fissile material, with masses as low as $7 \mathrm{~kg}$ only for very ideal conditions (enrichments greater than $80 \%$, no neutron posions, significant porosity that is near full saturation, etc.). However, these conditions are not likely to exist. Existing criticality studies for degraded and partially degraded internal geometries indicated that masses greater than $10 \mathrm{~kg}$ would be required for highly-enriched uranium (HEU) 
without neutron poisons under nominal conditions, and masses greater than $14.4 \mathrm{~kg}$ are needed for HEU when $1 \%$ of the original neutron poisons are remaining.

C) There are combinations of fissile mass and concentration (for enrichments greater than $20 \%$ ) for which it is technically possible to achieve delayed criticality in nearfield geometries that include a mixture of highly enriched fissile material and rust. However, the fissile concentrations (in the absence of neutron poisons) necessary to accomplish this are substantial (excess of $10 \mathrm{~kg} / \mathrm{m}^{3}$ ) and when considering the geochemistry in the repository environment and allowed fissile masses individual packages, it may not be plausible for these fissile concentrations to ever occur. PA results for container degradation will be needed to generate FEPs screening arguments for this scenario.

D) Results indicate that the presence of reflector material (the tuff host rock surrounding the critical zone) has a significant impact on the required critical mass but not on the fissile concentration. (Thus, the effect of the addition of a reflector is that the corresponding S-curve is translated down in fissile mass but not to the left or right in fissile concentration.) Models lacking in reflector geometries may slightly overestimate minimum required fissile masses.

\section{ES.5.2 Excursion Consequences}

A large parametric nuclear dynamics analysis was performed in this study using the DTHX and UDX models. The calculations were used to identify the relationship between net excursion fissions and criticality assembly parameters (i.e., mass, temperature feedback properties, etc.). These calculations were performed with these two models at different levels of detail. The more detailed model (DTHX) is termed "fully-coupled" nuclear dynamics. This model is sophisticated in that it couples the time behavior model for the neutron population (and hence power and fission production) with the transient multiphase model for the combined thermal hydrology and transport of unsaturated groundwater. The DTHX model is computationally intensive and is used for select studies for far-field criticality. The second consequence model is less detailed and is termed "Uncoupled" nuclear dynamics (UDX). This model analyzes only the time behavior of the neutron population and does not model spatial effects. Since it is computationally efficient, it was used for parametric sensitivity analysis. Comparison of this model to the "fully-coupled" nuclear dynamics indicated that its results are conservative (Figure ES-7) and can be used for bounding calculations. Since the uncoupled nuclear dynamics is not related to the spatial geometry of the fissile mass, its results are applicable to in situ, near-field, or far-field analysis. The UDX model results are used to identify the net impact upon the radiological source term due to a single nuclear excursion in terms of additional fission yield products. The nuclear dynamics calculations (DTHX and UDX) identified the following:

A) The number of net fissions from a typical excursion are very low and are similar to values previously experienced in criticality accidents involving aqueous solutions with fissile material. Typical net-fissions are computed to be in the range of $10^{17}$ to $10^{20}$ fissions per excursion. These computed values are in good comparison to published values for criticality accidents involving aqueous systems (see Frolov 1995, Paxton 1980, and Stratton 1989). 
B) When comparing "fully-coupled" nuclear dynamics DTHX computational results to "Uncoupled" nuclear dynamics (UDX) results, it was identified that UDX results are conservative (see Figure ES-7). Since the UDX model does not include groundwater modeling, which is computationally intensive, the UDX model was used to investigate the sensitivity of excursion fissions upon various neutronic model parameters. The UDX calculations resulted in the further understanding of the nuclear excursions and yielded a simple relationship (see Figure ES-8). An important feature of this relationship is that the number of net fissions is strongly dependent on the inventory of fissile material in a critical assembly. Since the fissile mass is limited by S-curve quantities, the fissions are expected to be very low for conceivable situations leading to an excursion.

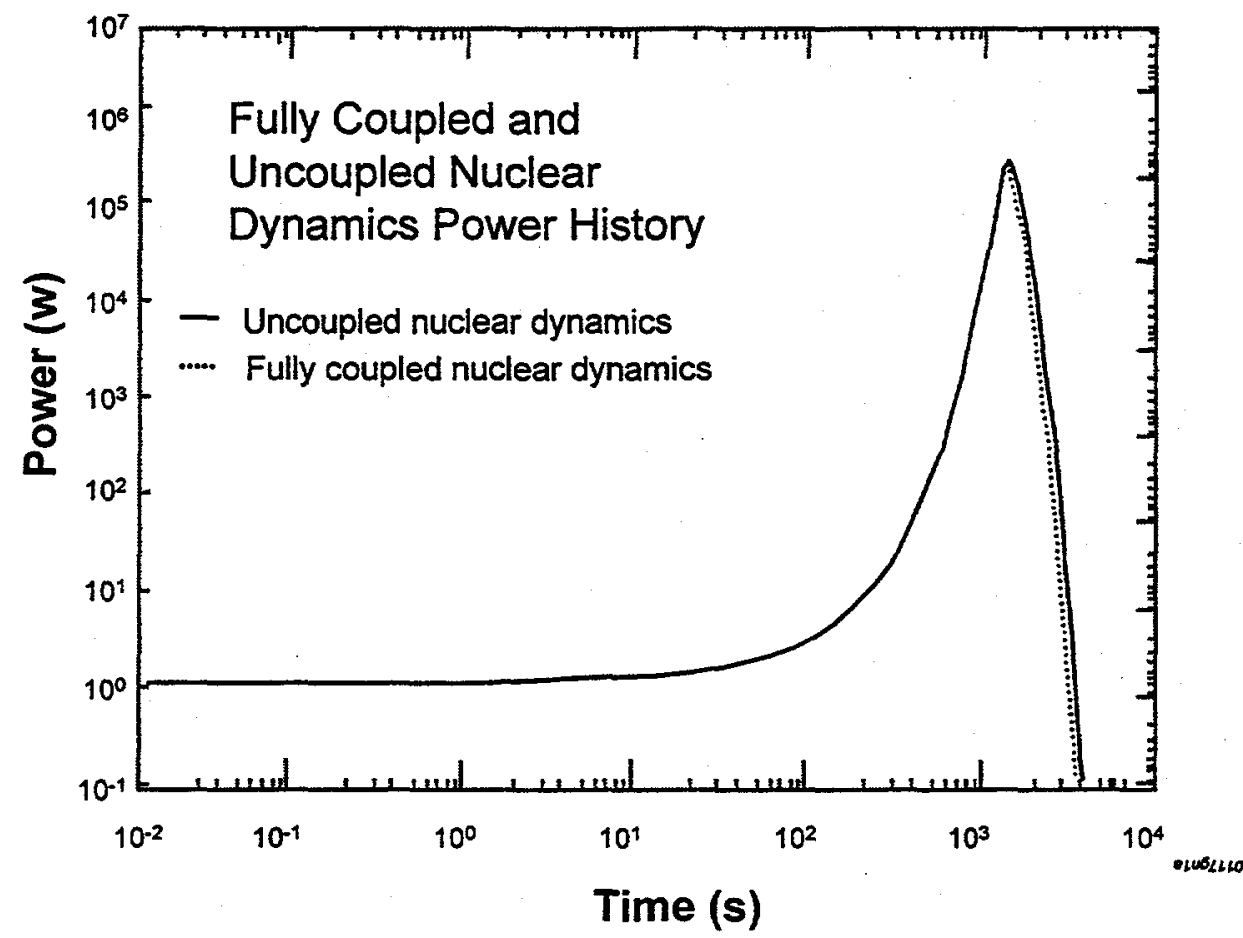

Figure ES-7. Comparison of fully-coupled nuclear dynamics results with uncoupled nuclear dynamics results. (Data for uranium in Topopah Springs tuff at nominal geologic conditions.) 


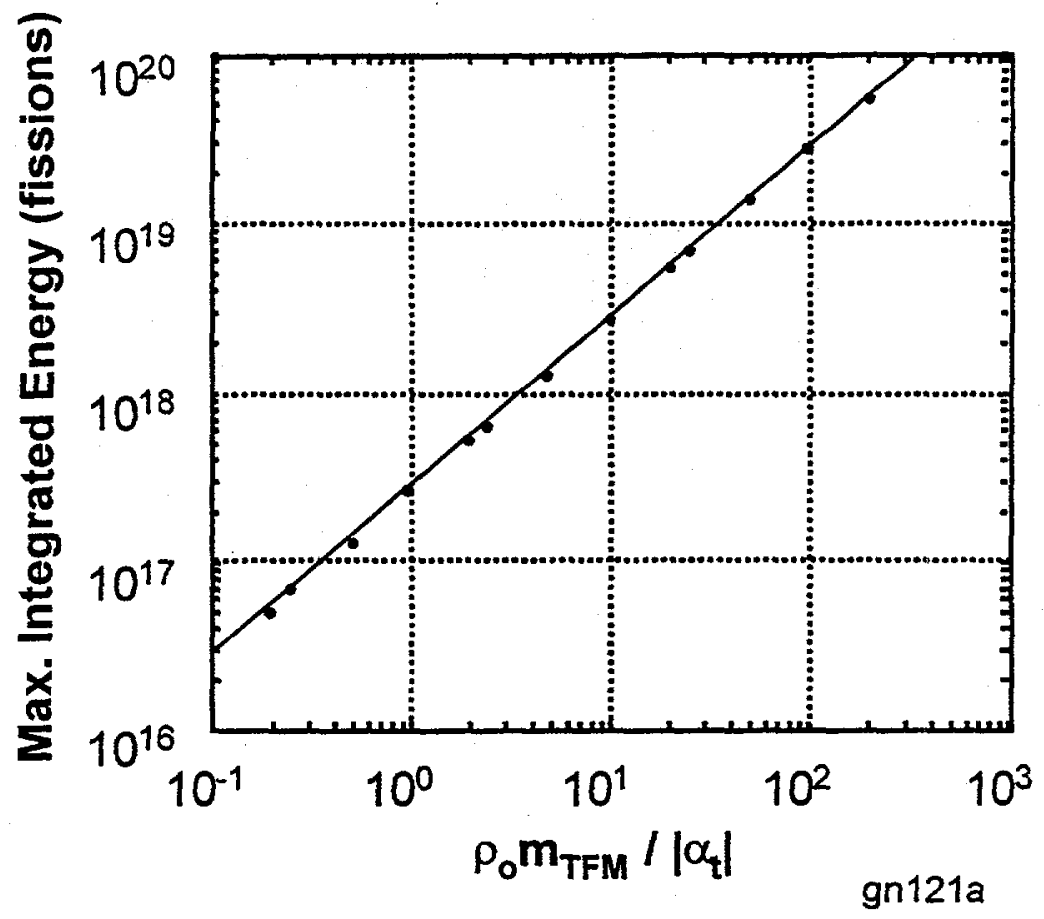

Figure ES-8. Scaling law for uncoupled nuclear dynamics calculations.

Figure ES-8 Nomenclature:

$\rho_{0}$ initial reactivity insertion $[\phi]$

$\mathrm{m}_{\mathrm{TFM}} \quad$ thermal fissile mass $[\mathrm{kg}]$

$\alpha_{\mathrm{t}}$ prompt temperature feedback coefficient $[\mathrm{pcm} / \mathrm{K}$ ]

\section{ES5.3. Thermal Hydrology Simulations}

A small parametric study was performed with the THX model to investigate the transient response of the repository media as if it experienced a nuclear excursion. Excursion power profiles correspond to typical energy released as predicted by the UDX and DTHX models. The thermal hydrology calculations were used for select far-field geometries to determine the temperature and saturation recycle times. (These correspond to the elapsed time after an excursion that is necessary to return to initial temperature and saturation conditions.) These calculations were used to estimate the frequency for multiple excursions that may occur after an initial critical assembly is generated. The thermal hydrology/groundwater transport calculations (THX) identified the following:

A) Even though the UDX and DTHX models indicated low net excursion fissions, there are significant groundwater temperature and saturation effects. Since it is necessary to restore the initial groundwater conditions to initiate another excursion, these effects are important in order to identify the bounding frequencies (recycle times) for occurrence of repeated nuclear excursions.

B) Computational results indicated that groundwater saturation recycle times are longer than groundwater temperature recycle times. Also the saturation times are 
significantly long and preclude a continuous "slow cooker" power operation. This is due mainly to the unpressurized characteristics of the unsaturated tuff host rock. Typical THX results can be seen in Figure ES-9.

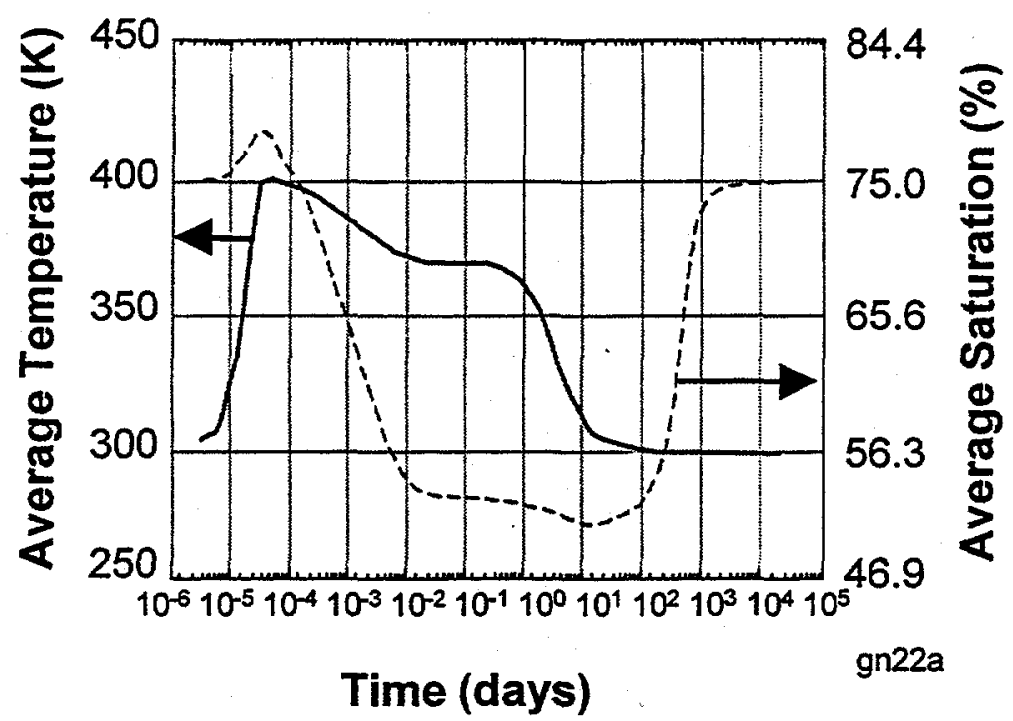

Figure ES-9. Typical thermal hydrology / groundwater transport computational results. (Data for uranium in Topopah Springs at nominal geologic conditions.)

\section{ES.5.4 Probability for Criticality Initiators}

A Monte Carlo simulation was performed in the PRA model for events (such as groundwater infiltration, container corrosion, etc.) that may cumulatively result in the generation of an initial criticality. These probability values, when multiplied with the consequences of multiple excursions (for only those SNFs that have the potential to yield a critical assembly), will yield "risk". The metric used in this study for risk is "additional fissions" which can be directly compared to the initial radiological source term. The PRA model added valuable information on the probability for an initial criticality. This PRA model, using the SLAM code, computed criticality probability frequencies under glacial and non-glacial conditions. The results indicated a "worst case" (under persistent glacial conditions) probability of 2.2 containers undergoing criticality over 100,000 year duration $\left(2.2 \times 10^{-5} / \mathrm{yr}\right)$. "Present day" conditions yielded a probability frequency of only 0.07 containers undergoing criticality over 100,000 year duration $\left(7 \times 10^{-7} / \mathrm{yr}\right)$. Thus the PRA model (using PA corrosion submodels and results) identified that these fissile masses and their corresponding concentrations have very small probabilities of occurrence.

\section{ES.5.5. General Results}

The major NDCA findings indicate that the disposal of DOE SNF in volcanic tuff typical of the Yucca Mountain Site (YMS) result in: (1) probability frequency of initial criticality of $7 \times 10^{-7}$ criticality initiators/yr (under present day conditions), (2) range of 3 to 30 criticalities/yr (limited by geohydrology), and (3) range of $10^{17}$ to $10^{20}$ fissions/criticality. Thus the nominal risk associated with criticality is given by: Risk = Consequences $\mathrm{x}$ 
Frequency $=5 \times 10^{18}$ (fissions/criticality) $\times 7 \times 10^{-7}$ (initial criticalities/yr) $\times 15$ (criticalities/yr-initial criticality) $\times 100 \mathrm{yr}$ (an assumed duration of repeated criticalities) $=$ $5.3 \times 10^{15}$ additional fissions per year. This risk is extremely small when compared to the initial YMS source term of $\sim 6 \times 10^{31}$ fissions.

\section{ES.6 Conclusions}

The risk values presented in this paper are comparable to previous estimates, even when using PRA model results at the ROM level. Updates to the PRA model are currently taking place, but they are not expected to significantly alter the net outcomes of the NDCA study. The overall finding of this report is that nuclear criticality is not a significant contributor to post-closure repository releases to the accessible environment. The NDCA study results indicate that it is nearly impossible to generate a critical assembly in near- and far-field geometries and that the risks of criticality are below the roundoff for the radionuclide inventory source term. Since the risks are below the "noise", there is no risk-based justification for application of criticality safety (k-effective $<0.95$ ) guidelines for repository post-closure conditions. Resources are better applied to engineered features that may reduce annual effective doses due to groundwater transport of radionuclide inventory.

\section{ES.7 Potential Benefits of Model Enhancements}

Much of the technical work in this study is based on preliminary data; thus the results have significant uncertainty. Future work is not likely to significantly affect the general implications of the technical findings, but it may aid in the defensibility of the models. There are three areas where NDCA model enhancements would be beneficial:

1) PRA Model

Upgrading the PRA model would result in better confidence for criticality probability frequencies. At present, the model uses preliminary corrosion data and incomplete corrosion submodels. These submodels are currently being upgraded within the Yucca Mountain PA project and may be available in the near future. These updated models along with refinement in the input data will aid the defensibility of the PRA model. Results, if accepted, should continue to indicate that criticality does not have a significant impact to the releases to the accessible environment.

2) Nuclear Cross Sections

Only for unique SNFs with enrichments close to pure U-235, nuclear cross sections may be processed for use in evaluating the Doppler temperature coefficient (DTC), which when combined with the leakage due to small changes in geometry (e.g., surface-to-volume ratio) results in the prompt feedback coefficient. This evaluation would only be necessary to show that the range of prompt feedback coefficients used in this study include the fuel type in question.

3) PA Results 
Use PA transport results for the transport of fissile and neutron poison materials to determine the mass and concentration of fissile material in an assembly. These data can be used directly in the FEPs screening arguments.

\section{ES.8 References}

[Frolov 1995]

V.V.. Frlov, B.G. Ryazanov, and V.I. Sviridov, "A Review of Criticality Accidents Which Occurred in the Russian Industry, "Proc. Of the Fifth International Conference on Nuclear Criticality Safety, Sept. 17-21, Aluquerque, NM. Pp. 234-30 1995.

[Paxton 1980]

H.C. Paxton, "Histrorical Perspective of Nuclear Criticality Safety in the United States," Proc. ANS Topl. Mtg. Nuclear Criticality Safety, El Paso, Texas, April 8-10, 1980, SAND80-1675, p. 21. Sandia National Laboratories, 1980.

[Stratton, 1989]

W.R. Stratton, revised by David R. Smith, A Review of Criticality Accidents. DOE/NCT04, March, 1989. 